SOSIOLIUM

\title{
PENGEMBANGAN APLIKASI GO SOCIAL BERBASIS ANDROID SEBAGAI MEDIA PEMBELAJARAN IPS PADA MATERI KEDATANGAN BANGSA-BANGSA BARAT KE INDONESIA KELAS VIII DI SMP NEGERI 11 SEMARANG
}

\author{
Dian Trihartini, Asep Ginanjar ${ }^{\bowtie}$ \\ Prodi Pendidikan IPS, Fakultas Ilmu Sosial, Universitas Negeri Semarang, Indonesia
}

\begin{abstract}
Info Artikel
Abstrak

Sejarah Artikel:

Disubmit: Juli 2021

Direvisi: Agustus 2021

Diterima: September 2021

\section{Keywords:}

Go Social Application;

Learning Media; Android;

Social Studies

Media pembelajaran merupakan alat bantu yang dapat digunakan siswa untuk memahami materi yang disampaikan oleh guru. Inovasi dalam penggunaan media pembelajaran yang menggunakan banyak aspek visual, akan lebih membantu siswa dalam memahami materi dibandingkan dengan narasi teks saja. Media pembelajaran aplikasi go social berbasis android ini berisikan materi Sejarah SMP kelas VIII yaitu materi kedatangan bangsa-bangsa barat ke Indonesia. Jenis penelitian yang digunakan yaitu penelitian pengembangan, dengan menggunakan model ADDIE. Hasil penelitian menunjukkan bahwa aplikasi go social berbasis android sebagai media pembelajaran IPS, masuk dalam kriteria sangat layak dan sangat praktis untuk digunakan sebagai media pembelajaran dengan penilaian yang diperoleh sebesar $89,41 \%$ dari ahli mater, $86,66 \%$ dari ahli media, dan $97,32 \%$ dari angket respon siswa. Diharapkan hasil penelitian ini dapat dikembangkan lebih lanjut dan dapat memenuhi kebutuhan siswa SMP kelas VIII di masa depan.
\end{abstract}

\begin{abstract}
Learning media is a tool that can be used by students to understand the material presented by the teacher. Innovation in the use of learning media that uses many visual aspects will help students understand the material more than just text narratives. This android-based go social application learning media contains material for the history of SMP class VIII, namely material for the arrival of western nations to Indonesia. The type of research used is development research, using the ADDIE model. The results showed that the android-based go social application as a social studies learning media was included in the very feasible and very practical criteria to be used as a learning medium with an assessment obtained of $89.41 \%$ from material experts, $86.66 \%$ from media experts, and $97.32 \%$ of the student response questionnaire. It is hoped that the results of this study can be further developed and can meet the needs of class VIII SMP students in the future.
\end{abstract}

\begin{tabular}{lc}
\hline Alamat korespondensi: & E-ISSN 2685-4929 \\
Gedung C1 Lantai 1 FIS Unnes & \\
Kampus Sekaran, Gunungpati, Semarang, 50229 & \\
E-mail: asepginanjar@mail.unnes.ac.id &
\end{tabular}




\section{PENDAHULUAN}

Pendidikan merupakan hal yang sangat penting bagi kehidupan manusia, dengan adanya pendidikan manusia dapat memperoleh pengetahuan, keterampilan dan keahlian yang dapat mengembangkan potensi yang dimilikinya. Pendidikan merupakan aspek utama terciptanya sumber daya manusia yang berkualitas, untuk itu pendidikan harus dilaksanakan dengan sebaikbaiknya sehingga sesuai dengan tujuan pendidikan nasional yang tercantum dalam UU Nomor 20 Tahun 2003 Bab II pasal 3. Dalam rangka meningkatkan kualitas pendidikan suatu bangsa, perlu adanya suatu inovasi dalam bidang pendidikan. Inovasi tersebut dapat dilakukan dengan memanfaatkan hasil-hasil teknologi ke dalam proses pembelajaran yang salah satunya dapat dimanfaatkan sebagai media pembelajaran

Media merupakan salah satu faktor penunjang tercapainya tujuan pembelajaran. Hamalik (dalam Sanaky, 2013) mengatakan bahwa media pembelajaran adalah alat, metode, dan teknik yang digunakan untuk lebih mengefektifkan komunikasi antara pengajar dan pembelajar dalam proses pembelajaran di kelas. Penggunaan media yang tepat dalam proses pembelajaran dapat meningkatkan motivasi belajar dan dapat mengurangi sikap pasif siswa.

Ilmu Pengetahuan Sosial (IPS) merupakan salah satu cabang sains yang tidak cukup hanya disampaikan dengan metode ceramah. Karena IPS merupakan mata pelajaran yang mempelajari berbagai rumpun ilmu sosial yang dijadikan satu kesatuan secara terpadu, sehingga media pembelajaran yang digunakan tidak hanya mengandalkan media cetak seperti buku paket ataupun LKS. Hasil analisis kebutuhan yang dilakukan di SMP Negeri 11 Semarang menunjukkan bahwa penggunaan media pembelajaran IPS masih belum up to date, karena media yang digunakan masih terbatas seperti video dan memanfaatkan lingkungan sekitar. Sehingga meskipun proses pembelajaran IPS sudah berlangsung dengan baik, namun kendalanya yaitu masih banyak siswa yang kurang minat dalam mempelajari pelajaran IPS.

Untuk mengatasi permasalahan tersebut, media pembelajaran yang digunakan harus dikemas semenarik mungkin agar siswa betah berlama-lama mempelajari suatu materi. Salah satu media pembelajaran yang dapat dipakai adalah penggunaan media pembelajaran berupa Aplikasi Android yang memungkinkan adanya teks, gambar, video dan animasi dalam sebuah tayangan.
Penggunaan telepon seluler berbasis android yang digunakan sebagai media pembelajaran IPS memiliki peluang besar. Karena hampir 90\% siswa SMP Negeri 11 Semarang sudah mempunyai telepon seluler berbasis android. Adanya aplikasi android yang dijadikan sebagai media pembelajaran ini, dapat mempermudah siswa dalam belajar. Siswa dapat mengatur sendiri waktu belajar dan tempat dari mana ia belajar, karena materi yang ada dalam aplikasi android ini, kapan pun dibuka akan tetap tersedia.

Berdasarkan latar belakang tersebut, maka peneliti tertarik melalukan penelitian dengan judul "Pengembangan Aplikasi Go Social Berbasis Android sebagai Media Pembelajaran IPS pada Materi Kedatangan Bangsa-Bangsa Barat Ke Indonesia Kelas VIII di SMP Negeri 11 Semarang".

Rumusan masalah dalam penelitian ini yaitu (1) Bagaimanakah desain awal atau prototype aplikasi go social berbasis android sebagai media pembelajaran IPS kelas VIII pada materi kedatangan bangsa-bangsa barat ke Indonesia?; (2) Bagaimanakah validasi dari validator ahli terhadap pengembangan aplikasi go social berbasis android sebagai media pembelajaran IPS kelas VIII pada materi kedatangan bangsa-bangsa barat ke Indonesia?; (3) Bagaimanakah hasil implementasi dan evaluasi pengembangan aplikasi go social berbasis android sebagai media pembelajaran IPS kelas VIII pada materi kedatangan bangsa-bangsa barat ke Indonesia?.

\section{METODE}

Jenis penelitian ini adalah penelitian pengembangan atau research and development (R\&D). Menurut Sugiyono (2014), metode penelitian dan pengembangan adalah metode penelitian yang digunakan untuk menghasilkan dan menguji keefektifan produk tertentu.

Model pengembangan yang digunakan dalam penelitian pengembangan ini adalah model ADDIE yang terdiri dari lima tahapan yaitu analysis, design, development, implementation, dan evaluation. Analysis berkaitan dengan kegiatan analisis situasi dan lingkungan sehingga ditemukan produk apa yang perlu dikembangkan. Design merupakan kegiatan perancangan produk sesuai dengan yang dibutuhkan. Development kegiatan pembuatan dan pengujian produk, Implementation kegiatan menggunakan produk, dan Evaluation kegiatan menilai apakah produk yang dibuat sudah sesuai dengan spesifikasi atau belum (Sugiyono, 2015). 
Instrumen pengumpulan data menggunakan metode observasi, wawancara, dan angket. Observasi digunakan untuk mengetahui keadaan sekolah, karakteristik peserta didik dan pelaksanaan pembelajaran IPS. Metode wawancara digunakan untuk mengetahui analisis kebutuhan, dan angket digunakan untuk mengetahui kesesuaian, ketepatan, kelayakan dan kepraktisan produk yang dikembangkan. Analisis data dalam penelitian pengembangan ini menggunakan analisis isi pembelajaran dan analisis statistik deskriptif.

\section{HASIL DAN PEMBAHASAN}

\section{Analisis Kebutuhan}

Tahapan awal yang dilakukan oleh peneliti sebelum mengembangkan media pembelajaran adalah analisis kebutuhan. Analisis kebutuhan dilakukan di SMP Negeri 11 Semarang menggunakan teknik observasi dan wawancara bersama guru mapel IPS dan beberapa siswa kelas 8, dengan tujuan untuk mengetahui serta mendapatkan informasi mengenai penggunaan media pembelajaran pada mata pelajaran IPS.

Berdasarkan hasil analisis kebutuhan menunjukkan bahwa dalam pelaksanaan pembelajaran IPS sudah menggunakan media pembelajaran, hanya saja media pembelajarannya masih belum up to date. Media pembelajaran yang digunakan masih terbatas seperti video yang didonwload dari youtube dan memanfaatkan lingkungan sekitar. Sementara itu, hasil wawancara yang dilakukan dengan beberapa siswa menunjukkan hasil bahwa siswa mengatakan lebih menyukai media pembelajaran yang sifatnya online atau dengan menggunakan smartphone. Karena menurut mereka, penggunaan smartphone sebagai media pembelajaran terasa lebih menarik sehingga tidak membosankan

Sehubungan dengan hasil analisis kebutuhan tersebut, peneliti menganalisis kebutuhan mengenai media pembelajaran yang diharapkan guru dan siswa dalam mata pelajaran IPS supaya dapat sesuai dengan kebutuhan dan karakteristik peserta didik dalam pembelajaran.

\section{Desain atau Perancangan}

Desain merupakan tahapan perancangan media. Tahap desain bertujuan untuk mengumpulkan semua data dan informasi yang telah didapatkan dan kemudian dikembangkan menjadi sebuah program. Desain yang dibuat dalam penelitian ini, harus disesuaikan berdasarkan analisis kebutuhan. Tahapan perancangan media ini, meliputi beberapa langkah yaitu: pembuatan desain media berupa prototype, penyusunan materi, penyusunan soal dan jawaban, serta pengumpulan tombol dan pembuatan background.

\section{Pengembangan}

Tahapan pengembangan ini peneliti melakukan pembuatan media pembelajaran aplikasi go social berbasis android sesuai dengan prototype yang telah dibuat pada saat tahap desain. Media pembelajaran aplikasi go social berbasis android dibuat menggunakan software Adobe Animate CC. Adobe Animate CC merupakan software professional yang digunakan untuk membuat beragam jenis proyek termasuk animasi, media interaktif, game, aplikasi smartphone, dll.

Aplikasi go social berbasis android yang sudah selesai diproduksi, selanjutnya dimuat dalam format file APK (.apk) sehingga nantinya dapat berjalan pada sistem operasi android, dan dapat diakses melalui https://bit.ly/3t1KGpT. Tahap pengembangan aplikasi go social berbasis android ini bertujuan untuk mengubah naskah media yang sudah disusun menjadi sebuah aplikasi yang berisi materi teks, gambar ilustrasi, animasi dan audio dengan format yang sesuai untuk diterapkan pada smartphone berbasis Android.

Setelah pengembangan aplikasi selesai, maka dilakukan validasi oleh validator ahli yaitu ahli materi dan ahli media. Tujuan dilakukan validasi dengan validator ahli adalah untuk mengetahui kekurangan dan memberikan penilaian terhadap aplikasi go social berbasis android. Validator ahli materi yaitu Bapak Dr. Arif Purnomo, S.Pd., S.S., M.Pd. yang merupakan dosen prodi Pendidikan IPS Universitas Negeri Semarang, dan validator ahli media yaitu Bapak Ghanis Putra Widhanarto S.Pd., M.Pd. yang merupakan dosen jurusan Kurikulum dan Teknologi Pendidikan Universitas Negeri Semarang.

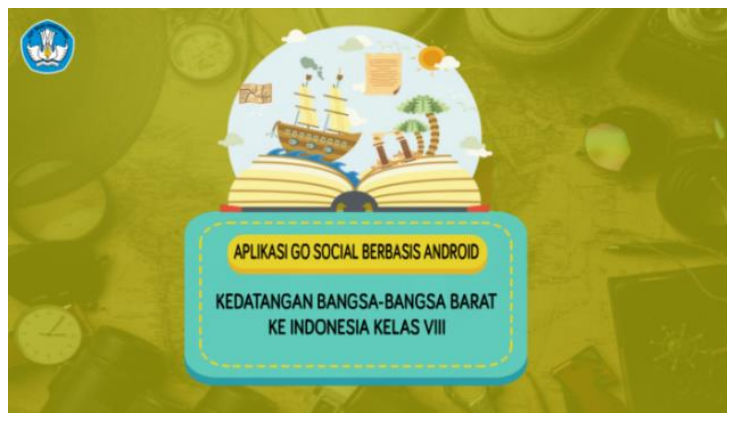

Gambar 1. Opening Aplikasi Go Social 
Aplikasi go social berbasis android memberikan pengalaman baru dalam proses pembelajaran IPS mengenai materi Kedatangan Bangsa-Bangsa Barat Ke Indonesia. Dengan berbasis android, aplikasi go social ini dapat digunakan sebagai media belajar dimanapun dan kapanpun. Sehingga dapat menciptakan pembeajaran mandiri bagi siswa.

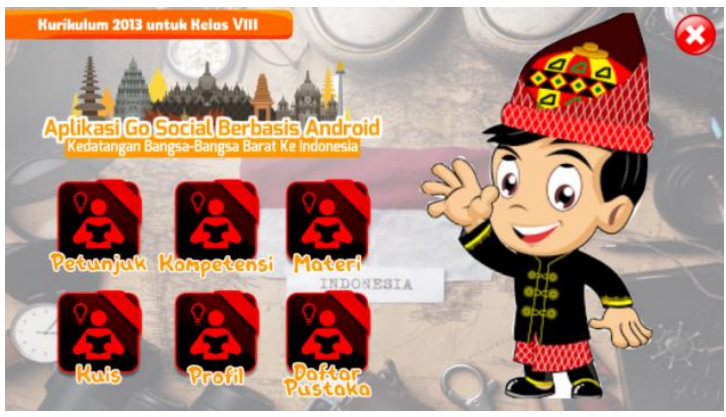

Gambar 2. Halaman Menu Utama Aplikasi

Halaman menu utama aplikasi go social berisi enam menu yang masing-masing menunya mempunyai fungsi berbeda. Enam menu tersebut yaitu petunjuk penggunaan, kompetensi, materi, kuis, profil pembuat, dan daftar pustaka atau referensi.

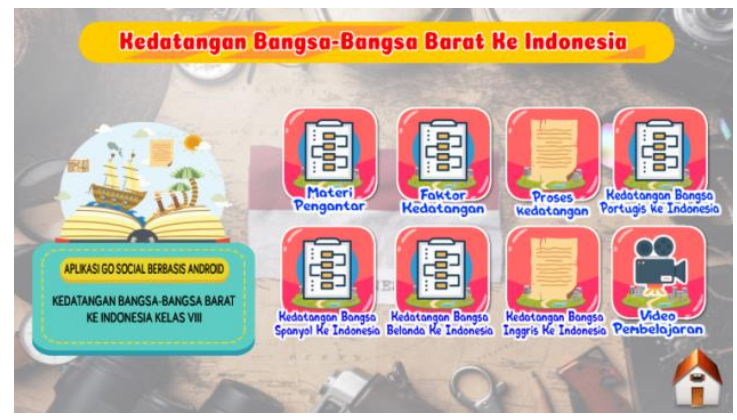

Gambar 3. Halaman Materi

Pada halaman materi terdapat delapan tombol sub materi yaitu materi pengantar, faktor kedatangan, proses kedatangan, kedatangan bangsa portugis, kedatangan bangsa spanyol, kedatangan bangsa belanda, kedatangan bangsa inggris dan video pembelajaran. Pada halaman materi ini, peserta didik dapat memilih sub materi yang akan dipelajari sehingga nantinya peserta didik dapat lebih memahami materi.

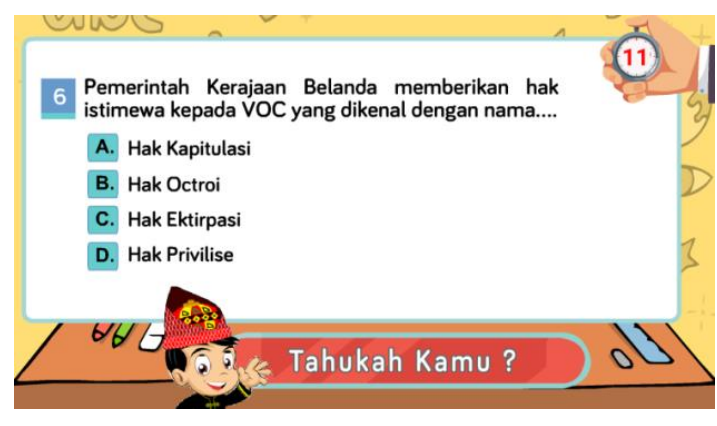

Gambar 4. Halaman Soal

Halaman soal merupakan tampilan dalam aplikasi go social yang menyajikan latihan soal yang dapat dikerjakan oleh pengguna (siswa), dengan tujuan sebagai evaluasi pengguna setelah mereka mempelajari materi sebelumnya. Latihan soal ini disajikan dengan memberikan 10 butir soal pilihan ganda kepada pengguna dengan waktu mengerjakan 20 detik setiap soal. Setelah pengguna selesai mengerjakan soal maka akan muncul hasil latihan berupa nilai dari kuis yang telah mereka kerjakan.

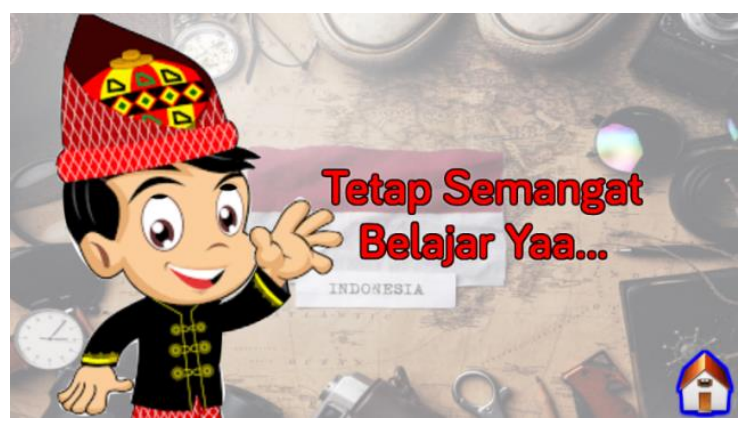

Gambar 5. Tampilan Keluar Aplikasi

Untuk keluar dari aplikasi go social, pengguna dapat menekan icon tombol $\mathrm{X}$ berwarna merah yang terdapat pada kanan atas menu utama aplikasi (gambar 2). Selanjutnya untuk keluar dari aplikasi, pengguna dapat menekan icon rumah yang ada dibagian kanan bawah.

Pada tahap pengembangan, aplikasi go social diberikan penilaian oleh ahli materi dan ahli media dengan tujuan untuk menilai kelayakan aplikasi supaya dapat diterapkan dalam proses pembelajaran. Masing-masing ahli diberikan angket berupa pernyataan mengenai isi dan komponen aplikasi go social. Berikut ini hasil penilaian ahli materi dan ahli media. 
Tabel 1. Penilaian Ahli Materi

\begin{tabular}{|c|c|c|c|c|}
\hline $\begin{array}{l}\mathrm{N} \\
\mathrm{o}\end{array}$ & Aspek & $\begin{array}{l}\text { Sko } \\
\mathrm{r}\end{array}$ & $\begin{array}{l}\text { Persenta } \\
\text { se }\end{array}$ & Ket \\
\hline 1 & $\begin{array}{l}\text { Relevansi } \\
\text { Materi }\end{array}$ & 20 & $100 \%$ & $\begin{array}{l}\text { Sang } \\
\text { at } \\
\text { layak }\end{array}$ \\
\hline 2 & $\begin{array}{l}\text { Pengorganisi } \\
\text { an Materi }\end{array}$ & 25 & $83 \%$ & $\begin{array}{l}\text { Sang } \\
\text { at } \\
\text { layak }\end{array}$ \\
\hline 3 & $\begin{array}{l}\text { Latihan } \\
\text { soal/quiz }\end{array}$ & 10 & $100 \%$ & $\begin{array}{l}\text { Sang } \\
\text { at } \\
\text { lavak }\end{array}$ \\
\hline 4 & Bahasa & 4 & $80 \%$ & $\begin{array}{l}\text { Laya } \\
\mathrm{k}\end{array}$ \\
\hline 5 & $\begin{array}{l}\text { Efek bagi } \\
\text { Strategi } \\
\text { Pembelajaran }\end{array}$ & 17 & $85 \%$ & $\begin{array}{l}\text { Sang } \\
\text { at } \\
\text { layak }\end{array}$ \\
\hline
\end{tabular}

Sumber: Data Primer, 2021

Tabel 2. Penilaian Ahli Media

\begin{tabular}{|c|c|c|c|c|}
\hline $\begin{array}{l}\mathrm{N} \\
\mathrm{O}\end{array}$ & Aspek & $\begin{array}{c}\text { Sko } \\
\mathrm{r}\end{array}$ & $\begin{array}{l}\text { Persentas } \\
\mathrm{e}\end{array}$ & Ket \\
\hline 1 & Bahasa & 8 & $80 \%$ & Lavak \\
\hline 2 & $\begin{array}{l}\text { Efek bagi } \\
\text { Strategi } \\
\text { Pembelajara } \\
\text { n }\end{array}$ & 8 & $80 \%$ & Layak \\
\hline 3 & $\begin{array}{l}\text { Rekayasa } \\
\text { Perangkat } \\
\text { Lunak }\end{array}$ & 19 & $195 \%$ & $\begin{array}{l}\text { Sanga } \\
\mathrm{t} \\
\text { layak }\end{array}$ \\
\hline 4 & $\begin{array}{l}\text { Tampilan } \\
\text { Visual }\end{array}$ & 30 & $86 \%$ & $\begin{array}{l}\text { Sanga } \\
\mathrm{t} \\
\text { layak }\end{array}$ \\
\hline
\end{tabular}

Sumber: Data Primer, 2021

Uji kelayakan aplikasi go social berbasis android dilakukan oleh ahli materi yaitu Bapak Dr. Arif Purnomo, S.Pd., S.S., M.Pd. selaku dosen Prodi Pendidikan IPS UNNES yang mengajar tentang materi-materi sejarah. Angket terdiri dari 5 aspek dan dijabarkan menjadi 17 indikator penilaian. Hasil penilaian aplikasi go social berbasis android adalah sangat layak untuk digunakan ke dalam proses pembelajaran, dengan mendapat total nilai sebesar 76 dan persentase sebesar $89,41 \%$.

Selanjutnya uji kelayakan produk aplikasi go social berbasis android dilakukan oleh ahli media yaitu Bapak Ghanis Putra Widhanarto S.Pd., M.Pd. selaku dosen Jurusan Teknologi Pendikan UNNES yang telah berpengalaman dalam pembuatan media pembelajaran. Angket terdiri dari 4 aspek dan dijabarkan menjadi 15 indikator penialian. Ahli media memberikan penilaian setelah menginstall, melihat, mencoba dan mengevaluasi media aplikasi go social berbasis android. Hasil penilaian aplikasi go social berbasis android adalah sangat layak untuk digunakan ke dalam proses pembelajaran, dengan mendapat total nilai sebesar 65 dan persentase sebesar $86,66 \%$

\section{Implementasi}

Implementasi dilakukan dengan menyebarkan media pembelajaran kepada 32 siswa kelas VIII G SMP Negeri 11 Semarang. Sebelum media digunakan siswa terlebih dahulu diminta untuk menginstall aplikasi go social pada smartphone masing-masing. Penyebaran media dilakukan melalui link google drive yang dibagikan melalui whatsapp group kelas VIII G. Setelah siswa selesai menginstall dan menggunakan media tersebut, selanjutnya siswa diminta untuk mengisi angket respon siswa yang telah diberikan melalui link google form. Berikut disajikan rekapitulasi jawaban dari siswa kelas VIII G SMP Negeri 11 Semarang.

\begin{tabular}{|c|c|c|c|c|c|}
\hline \multirow{2}{*}{ No } & \multirow{2}{*}{ Indikator } & \multicolumn{2}{|c|}{ Jawaban } & \multirow{2}{*}{ Jumlah } & \multirow{2}{*}{$\begin{array}{c}\text { Persentasi } \\
\text { Jawaban } \\
\text { Ya }\end{array}$} \\
\hline & & $\mathrm{Ya}_{\mathrm{a}}$ & Tidak & & \\
\hline 1 & $\begin{array}{l}\text { Aplikasi go social } \\
\text { memudahkan dalam } \\
\text { belajar }\end{array}$ & 31 & 1 & 32 & $96,87 \%$ \\
\hline 2 & $\begin{array}{l}\text { Petunjuk penggunaan } \\
\text { media mudah dimengerti }\end{array}$ & 31 & 1 & 32 & $96,87 \%$ \\
\hline 3 & $\begin{array}{l}\text { Bahasa yang digunakan } \\
\text { mudah dipahami }\end{array}$ & 32 & 0 & 32 & $100 \%$ \\
\hline 4 & $\begin{array}{l}\text { Ukuran dan jenis huruf } \\
\text { yang digunakan mudah } \\
\text { dibaca }\end{array}$ & 32 & 0 & 32 & $100 \%$ \\
\hline 5 & $\begin{array}{l}\text { Materi pada media dapat } \\
\text { menambah pengetahuan } \\
\text { dan wawasan }\end{array}$ & 32 & 0 & 32 & $100 \%$ \\
\hline 6 & $\begin{array}{l}\text { Penggunaan aplikasi go } \\
\text { social menyenangkan }\end{array}$ & 30 & 2 & 32 & $93,75 \%$ \\
\hline 7 & $\begin{array}{l}\text { Go social dapat } \\
\text { meningkatkan motivasi } \\
\text { belajar }\end{array}$ & 30 & 2 & 32 & $93,75 \%$ \\
\hline \multicolumn{4}{|c|}{ Rata-rata } & \multicolumn{2}{|c|}{$97,32 \%$} \\
\hline \multicolumn{4}{|c|}{ Kriteria } & \multicolumn{2}{|c|}{ Sangat Praktis } \\
\hline
\end{tabular}

Sumber: Data Primer yang diolah

bahwa seluruh pertanyaan mendapatkan respon positif dan dari 7 pertanyaan, siswa memberikan respon jawaban "ya" mendapat rata-rata sebesar 97\%. Persentase tersebut termasuk ke dalam kriteria yang sangat praktis untuk digunakan dalam pembelajaran.

\section{Evaluasi}

Tahapan evaluasi pada penelitian dan pengembangan ini, diperoleh dari saran, pendapat dan masukan yang diberikan oleh validator ahli terhadap aplikasi go social berbasis android. Hasil saran, pendapat, dan masukan tersebut digunakan oleh peneliti untuk melakukan revisi produk yang dikembangkan. 


\section{SIMPULAN}

Berdasarkan hasil penelitian dan pembahasan yang telah dijelaskan, maka dapat ditarik simpulan sebagai beirkut: Penelitian pengembangan yang telah dilakukan menghasilkan sebuah produk yaitu aplikasi go social berbasis android sebagai media pembelajaran untuk kelas VIII pada materi kedatangan bangsa-bangsa barat ke Indonesia. Pengembangan aplikasi go social ini menggunakan model ADDIE yang terdiri dari lima tahapan yaitu analysis (analisis), design (desain), development (pengembangan), implementation (implementasi), dan evaluation (evaluasi).

Hasil uji kelayakan aplikasi go social berbasis android pada materi kedatangan bangsabangsa barat ke Indonesia berdasarkan penilaian ahli materi mendapat nilai total 76 dengan persentase nilai $89,41 \%$, berdasarkan penilaian ahli media mendapat nila total 65 dengan persentase kelayakan $86,66 \%$, dan berdasarkan angket respon siswa mendapat nilai sebesar $97 \%$. Artinya dari hasil tersebut dapat diketahui bahwa aplikasi go social masuk ke dalam kriteria sangat layak dan sangat praktis untuk digunakan sebagai media pembelajaran dalam proses pembelajaran IPS.

\section{DAFTAR PUSTAKA}

Branch, Robert M. 2009. Instructional Design: The ADDIE Approach. New York: Springer.

Fachrizal, Muhammad dan Agus Sudarsono. 2018. Pengembangan Media Pembelajaran IPS Berbasis Aplikasi Android dalam Materi Kolonialisme dan Imperialisme Barat untuk Siswa SMP Kelas VIII. Dalam SOCIAL STUDIES. Vol. 7 No. 6. Hal. 583-595.
Lidiyasari, Tenti dan Yuli Utanto. 2020. Pengembangan Aplikasi Coda Pembelajaran Mandiri Pemrograman Dasar HTML Berbasis Mobile Learning. Dalam IJCETS. Vol. 5 No. 1. Hal. 1-12.

Oktiana, Gian Dwi. 2015. 'Pengembangan Media Pembelajaran Berbasis Android dalam Bentuk Buku Saku Digital Untuk Mata Pelajaran Akuntansi Kompetensi Dasar Membuat Ikhtisar Siklus Akuntansi Perusahaan Jasa di Kelas XI MAN 1 Yogyakarta Tahun Ajaran 2014/2015'. Skripsi. Universitas Negeri Yogyakarta: Fakultas Ekonomi.

Sanaky, Dr. Hujair AH. 2013. Media Pembelajaran Interaktif-Inovatif. Yogyakarta: Kaukaba Dipantara.

Sari, Vivi Melina. 2019. 'Pengembangan Multimedia Berbasis Android untuk Kompetensi dasar Pengukuran Listrik di Sekolah Menengah Kejuruan'. Skripsi. Universitas Negeri Yogyakarta: Fakultas Teknik.

Sugiyono. 2014. METODE PENELITIAN PENDIDKAN (Pendekatan Kuantitatif, Kualitatifdan R\&D). Bandung: Alfabeta.

Undang-undang Republik Indonesia Nomor 20 Tahun 2003 tentang Sistem Pendidikan Nasional. 2003. Jakarta: Diperbanyak oleh pusdiklat.perpusna.go.id. 